\title{
OPTIMAL TORQUE RIPPLE CONTROL OF ASYNCHRONOUS DRIVE USING INTELLIGENT CONTROLLERS
}

\author{
J.N.Chandra Sekhar 1 and Dr.G.V Marutheswar 2 \\ ${ }^{1}$ Department of EEE, Assistant Professor, S V University College of Engineering, \\ Tirupati-517502 \\ ${ }^{2}$ Department of EEE, Professor, S V University College of Engineering, Tirupati-517502
}

\begin{abstract}
The dynamic performance of an asynchronous machine when operated with cascaded Voltage Source Inverter using Space Vector Modulation (SVM) technique is presented in this paper. A classical model of Induction Motor Drive based on Direct Torque Control (DTC) method is considered which displays appreciable run-time operation with very simple hysteresis control scheme. Direct control of the torque and flux variables is achieved by choosing suitable inverter voltage space vector from a lookup table. Under varying torque conditions the performance of the drive system is verified using MATLAB/Simulink software tool. The ripple content in the torque parameter is significant when traditional PI controller and Fuzzy approach are configured in the proposed system. Finally, by replacing the PI-Fuzzy controller with Hybrid Controller the torque ripple minimization can be achieved during no-load and loaded conditions.
\end{abstract}

\section{KEYWORDS}

Direct torque control (DTC), Induction Motor (IM), Cascaded Voltage Source Inverter(VSI), Space vector modulation (SVM), PI controller, Fuzzy logic controller (FLC), Hybrid controller.

\section{INTRODUCTION}

In conventional electrical drive systems which are employed for variable speed applications, the utilization of dc motor is mostly preferred. A typical Motor-Generator arrangement is used to serve the need of wide range speed control systems. However the present electrical drive models are mostly configured with ac motor due to its appreciable operational features which outraced the dc motors in industrial applications [1].

Multilevel inverters with their working effectiveness are more prefered for the next generation medium voltage and high power applications. One popular arrangement such as a three-level Cascaded inverter also called as $\mathrm{H}$-Bridge inverter is used in the present paper. The output voltage waveforms in these inverters can be generated at low switching frequencies with high efficiency and minimum distortion. In the recent years, multilevel inverters employing various pulse width modulation (PWM) techniques have been developed. Among these techniques Space Vector Modulation (SVM) technique is considered as the best method because of its effective utilization of dc link voltage, reduced current ripple and easy implementation. This technique results in higher magnitude of fundamental output voltage as compared to Sinusoidal

DOI : 10.14810/elelij.2016.5301 
PWM. Also, in SVM method the degree of complexity increases with the increase in the level of inverters since many inverter switching states have to be handled [12].

Induction motor is an asynchronous variable speed ac motor well suited for medium and high power applications. The low cost and most widely used induction motor type is the squirrel cage motor [2]. Basically, the control design and estimation of ac drives is significantly complex than that of dc drives, and complexity increases highly if better performances are demanded. So, Induction motors have been widely used more in the industrial field for variable speed drive systems. Though the vector control strategy served for industrial demand, due to its significant demerits, the Direct Torque Control method is being implemented effectively.

The control and estimation of ac drives is considerably complex than those of dc drives. Conventional approaches like PI controller have been inefficient for various constraints such as unsuitable converter power supplies, non linearity of the machine model and motor parameter variations and frequency variations. Further an advanced control technique like fuzzy Logic Controller (FLC) can be used for the optimal control of the drive. Fuzzy logic systems have shown a simple approach in solving numerous non-linear problems and generated quite interest in certain applications. A fuzzy control model is based on a set of fuzzy rules which are linguistic ifthen statements and hence bypass the requirement of relying on mathematical approach [3]. The combinational feature of PI and FLC is a possible solution in dealing with the effects produced by the subsequent load variations.

\section{MATHEMATiCAL MOdEL OF THE INDUCTION MOTOR}

Equations describing the Stator model of the Motor:

$$
\begin{aligned}
& V_{d s}=R_{s} i_{d s}+\frac{d \lambda_{d s}}{d t}+\omega \lambda_{q s} \\
& V_{q s}=R_{s} i_{q s}+\frac{d \lambda_{q s}}{d t}+\omega \lambda_{d s}
\end{aligned}
$$

Equations describing the Rotor model of the Motor:

$$
\begin{aligned}
& V_{d r}=R_{r} i_{d r}+\frac{d \lambda_{d r}}{d t}-\left(\omega-\omega_{r} \lambda_{q r}\right) \\
& V_{q r}=R_{r} i_{q r}+\frac{d \lambda_{q r}}{d t}+\left(\omega-\omega_{r}\right) \lambda_{d r}
\end{aligned}
$$




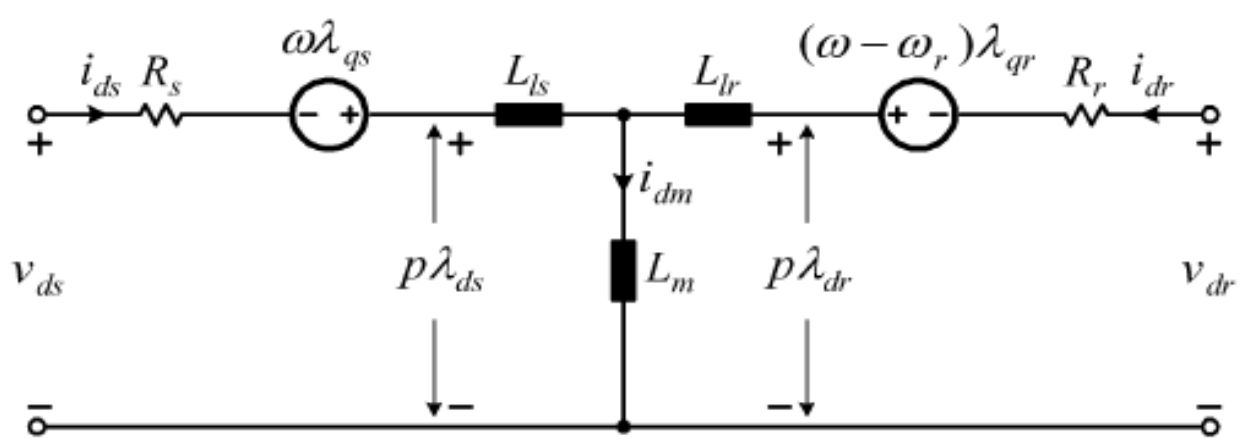

(a) $d$-axis

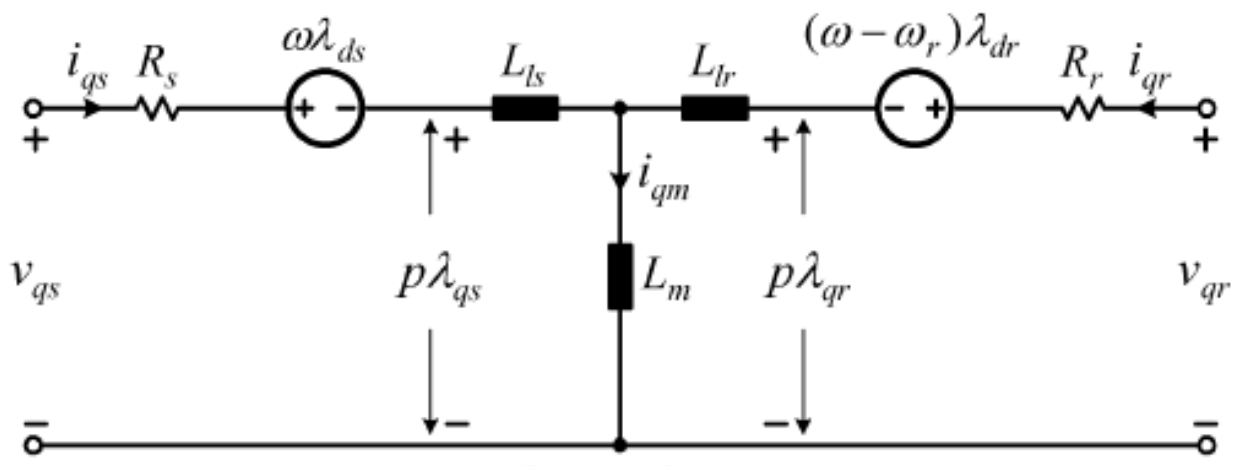

(b) $q$-axis

Fig 1: Dynamic $d^{e}-q^{e}$ equivalent circuits of Machine (a) $d^{e}$-axis and (b) $q^{e}-$ axis.

The electromagnetic torque developed by the interaction of air gap rotating flux and rotor mmf is represented with regard to the $\mathrm{d}-\mathrm{q}$ axis model as

$$
T_{e}=\frac{3}{2}\left(\frac{p}{2}\right)\left(\lambda_{d s} i_{q s}-\lambda_{q r} i_{d r}\right)
$$

\section{Proposed System}

Direct Torque Control (DTC) is a good speed control scheme with simple structure used commonly in Induction Motor drive system. In such method the suitable selection of the inverter switching states supports the enhaced performance feature of the system [12]. Inverter switching vectors are selected from look up table from the torque and flux errors which are passed through by the hysteresis band limits

Proposed by Takahashi in the mid 1980's, the Direct Torque Control (DTC) provides good dynamic reponse and has spread its presence effectively in the field of industrial and automobile applications. The unoptimized effects of flux and torque amplitudes subjected to the hysteresis band controllers along with high ripples attracts the interests of research community. In Fig.2, conventional DTC control is shown. 


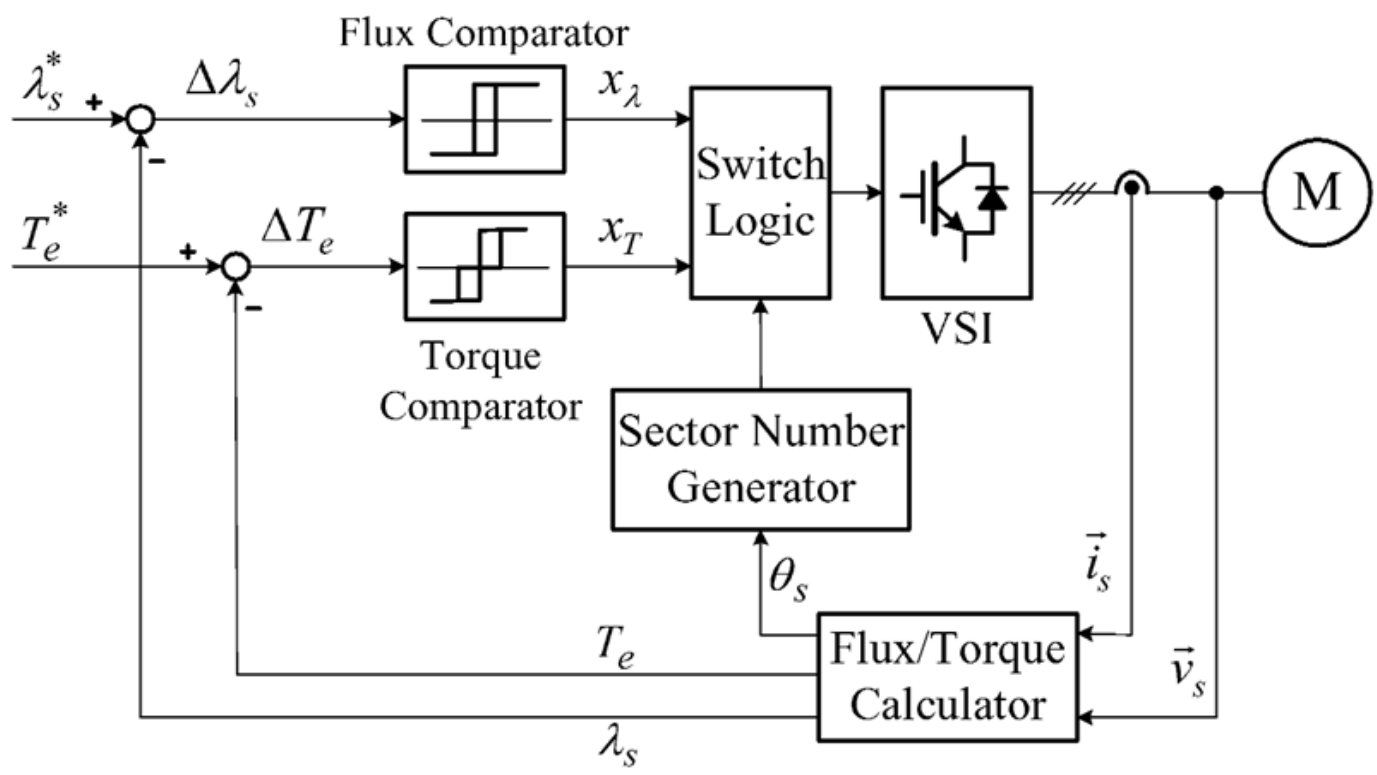

Fig 2: Block Diagram of Conventional Direct Torque Control.

\subsection{Three Level Cascaded Multilevel Inverter}

A Voltage Source Inverter (VSI) is a power electronic circuit which converts a stiff dc voltage to a 3- $Q$ ac voltage with variable frequency and amplitude [10]. Basically a two-level VSI consists of 6 groups of fast acting semiconductor switches and in contrast a three-level inverter consists of 12 groups of such switches. Depending on the direct current (DC) operating voltage of the inverter, each switch group consists of two or more IGBT or GCT or any switching devices connected in series. In this paper three level VSI are used in SVM DTC technique. The three level inverter configuration using cascaded two two-level inverters is shown in Fig. 3.

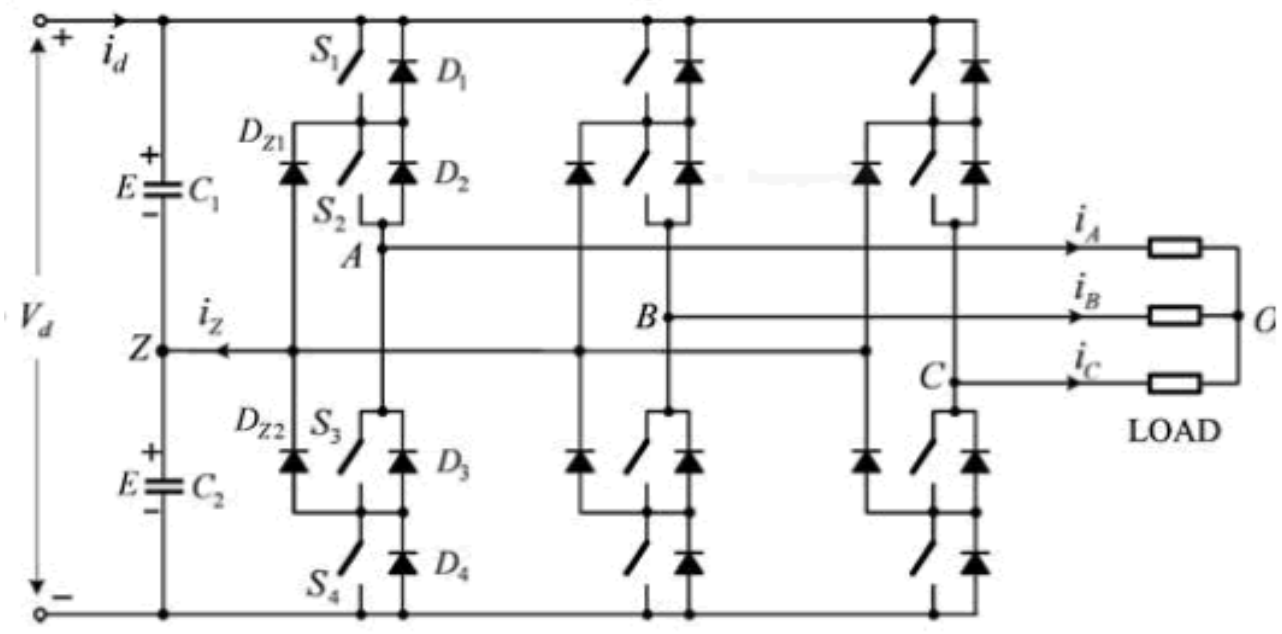

Fig 3: Three level inverter configuration 


\subsection{Space Vector Modulation (SVM):}

Space Vector Pulse width Modulation (SVPWM) is an advanced method with intensive computational feature and is best suited for variable speed drive applications. This method considers a sinusoidal voltage as a phasor which rotates with fixed angular frequency $(\omega)$. The output voltage of a $3-\propto$ VSI is produced by the vector sum of three modulating voltage signals which is given by the following equation [7].

$$
V_{r e f}=\frac{2}{3}\left(V_{a}+a V_{b}+a^{2} V_{c}\right)
$$

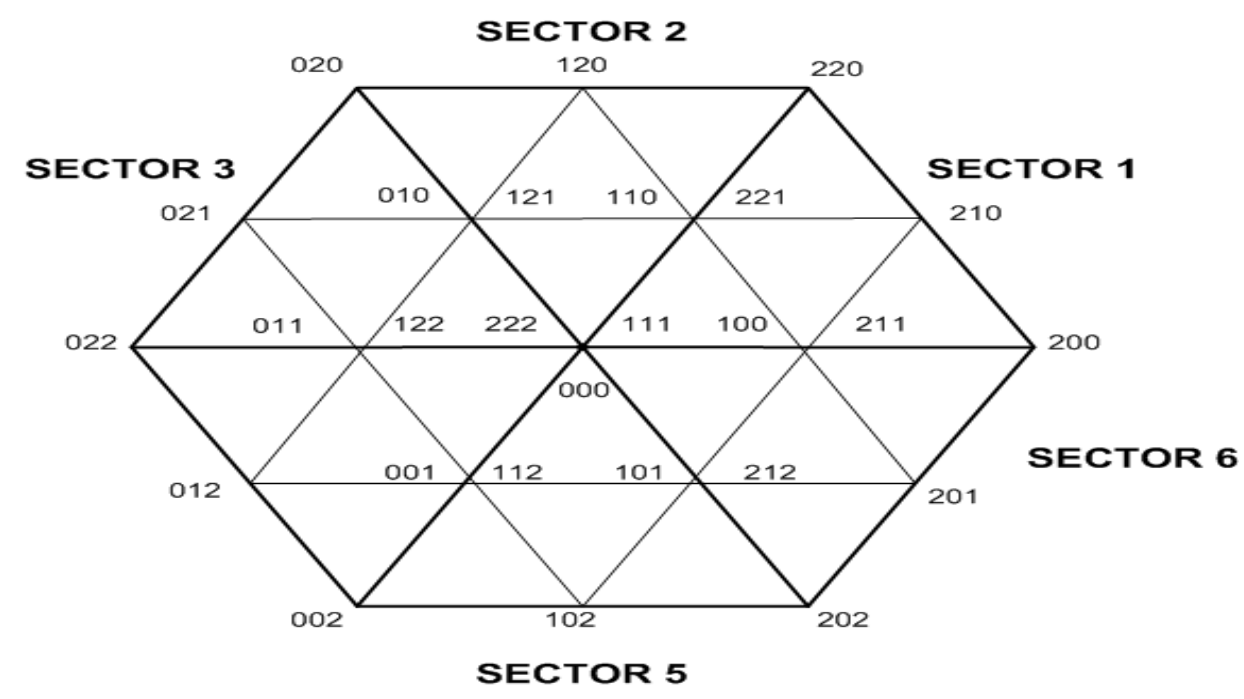

Fig 4: Sectors and their regions for Three-level Inverter

\section{Configurable controllers}

\subsection{PI Controller:}

A PI controller is a typical traditional controller which is generally intended to minimize the steady state error with increased type and order of the system. The output quantity of PI controller has two parts, one part is proportional to the input quantity and the other is proportional to the integral of the input quantity.

$$
q=K_{i} \int_{0}^{T} e(t) d t+K_{p} e(t)
$$

\subsection{Fuzzy-Controller:}

A fuzzy logic system describes the control algorithm which derives a fuzzy relation between input information to the expertise control action based on human experience [8]. In the proposed model, the fuzzy system has two inputs $\mathrm{E}(\mathrm{n})$ and $\mathrm{dE}$ (n) each defined with seven fuzzy sets. The 
output of the system is represented as V (n) defined with nine fuzzy sets. Generally a fuzzy set comprises a universe of discourse and a membership function(triangular function) that maps each element holding a membership value ranging from 0 to 1 . Fuzzification referes to a mathematical procedure which convertsan element in the universe of discourse into the membership value of the fuzzy set. Mamdani minimum inference method is considered for this system and finally to convert the fuzzy set to a real number, Centroid method of defuzzification is used.

T able 1: Rule Base for Fuzzy Logic Controller

\begin{tabular}{|c|c|c|c|c|c|c|c|}
\hline E & NB & NM & NS & ZE & PS & PM & PB \\
\hline NB & NB & NB & NB & NM & NS & NVS & ZE \\
\hline NM & NB & NB & NM & NS & NVS & ZE & PVS \\
\hline NS & NB & NM & NS & NVS & ZE & PVS & PS \\
\hline ZE & NM & NS & NVS & ZE & PVS & PS & PM \\
\hline PS & NS & NVS & ZE & PVS & PS & PM & PB \\
\hline PM & NVS & ZE & PVS & PS & PM & PB & PB \\
\hline PB & ZE & PVS & PS & PM & PB & PB & PB \\
\hline
\end{tabular}

\subsubsection{Fuzzy Control Action}

For the control signals involved in the fuzzy system namely error signal (E), the change in error signal $(\mathrm{dE})$ and the control input error $\mathrm{dC}$, the following equation describes the defined procedure: $\mathrm{C}(\mathrm{k})=\mathrm{C}(\mathrm{k}-\mathrm{l})+\mathrm{dC}(\mathrm{k})$ where $\mathrm{k}$ represents the sampling instant.

\subsection{Hybrid Controller:}

The hybrid controller comprises of PI-controller and Fuzzy Logic Controller connected in parallel. Such an arrangement has the advantages of both PI and Fuzzy Logic controller. Fuzzy logic assists the actual speed to get close to the reference speed, which compensate the reference speed given to PI controller with reference to rotor speed [5]. 


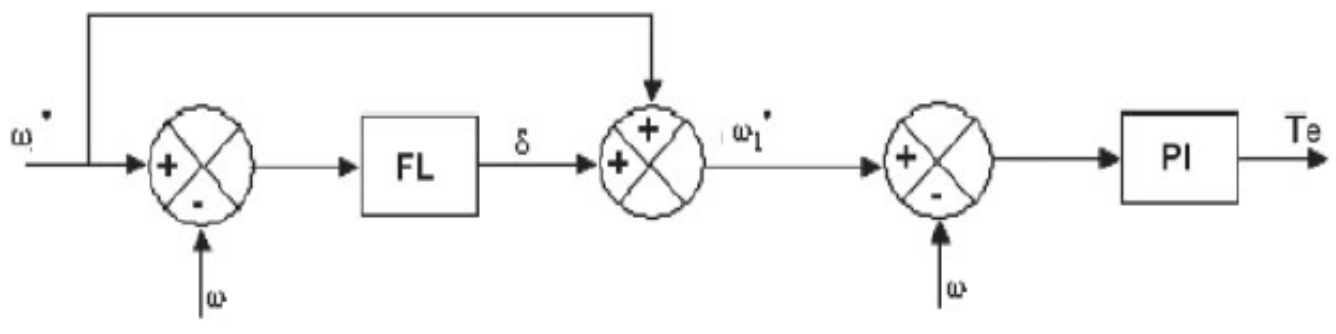

Fig 5: Block Diagram of Hybrid Controller.

\section{Simulation RESUltS AND DisCUSSION}

Using MATLAB/Simulink tool SVM based DTC of 3- $\bullet$ induction machine has been simulated with no-load and loaded torque cases. The simulation results display the operation of the variable speed drive in motoring mode and braking mode.

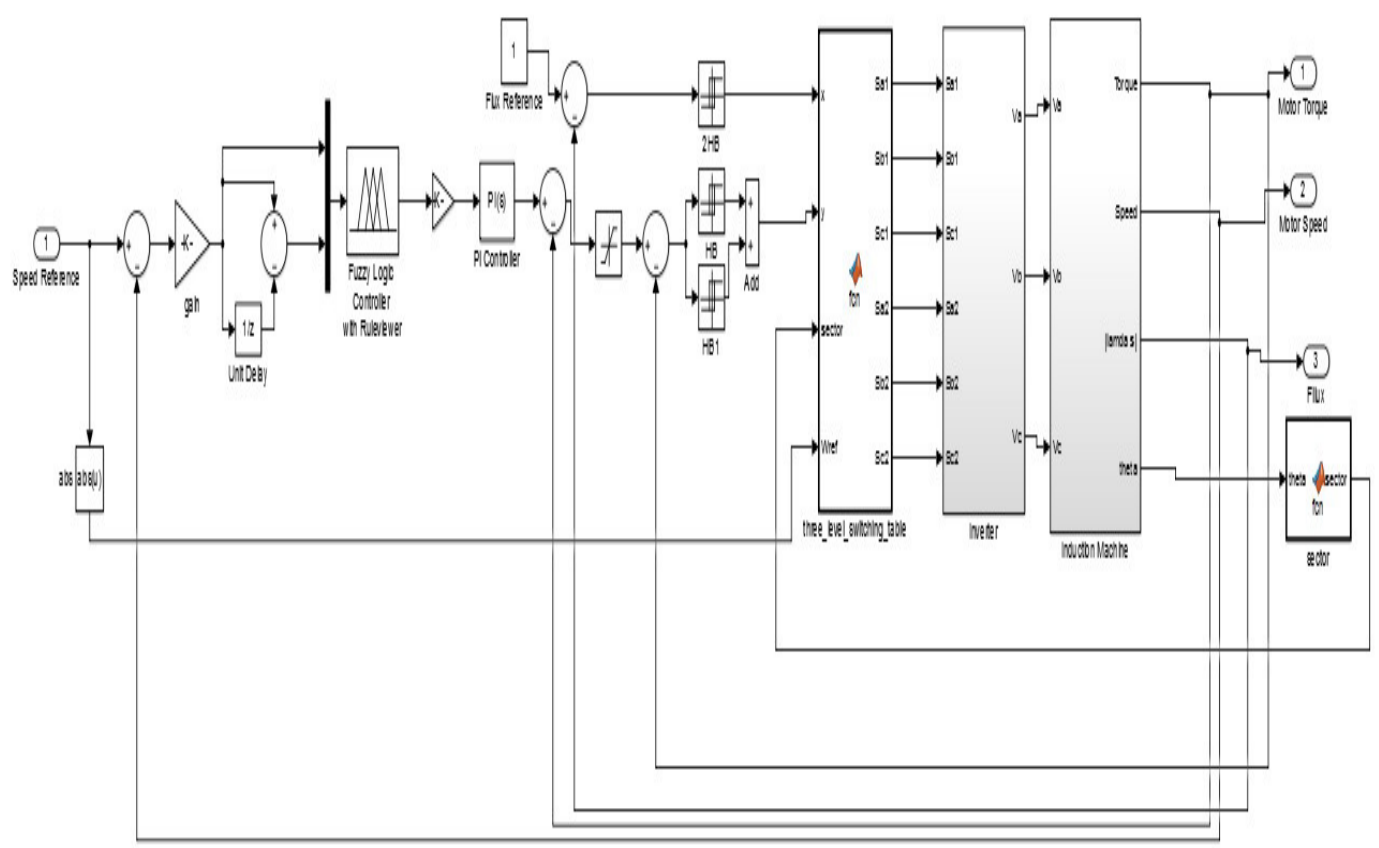

Fig 6: Simulink block diagram for the proposed method (SVM-DTC using Hybrid-Fuzzy plus PI controller). 
Electrical and Electronics Engineering: An International Journal (ELELIJ) Vol 5, No 3, August 2016

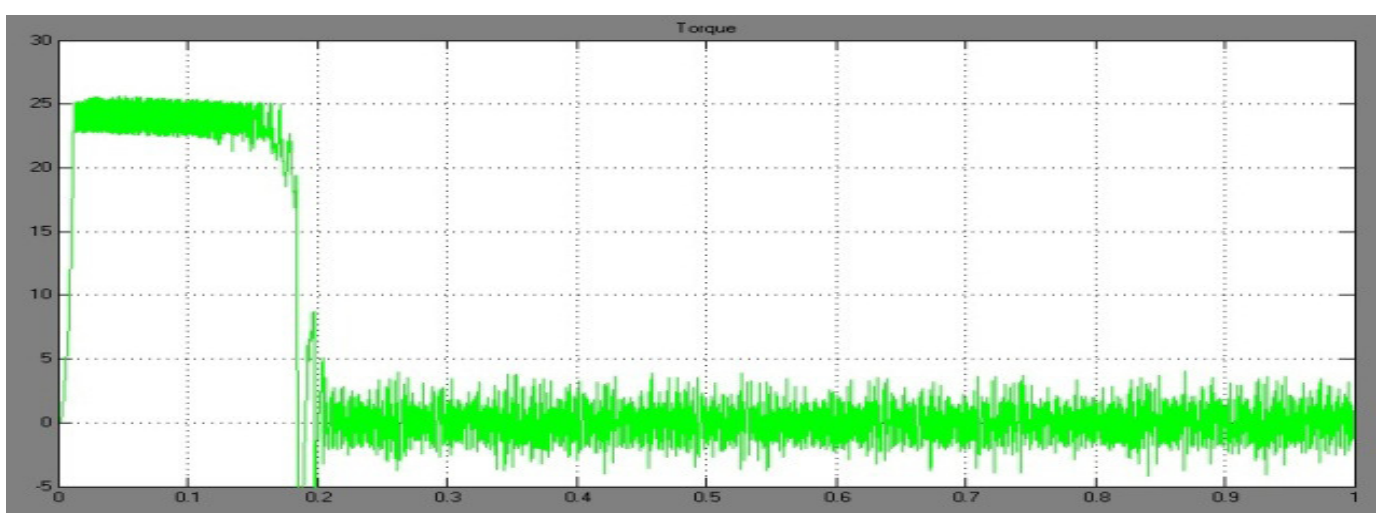

Fig 7: No load response for PI controller based SVM DTC at fixed speed $150 \mathrm{rad} / \mathrm{sec}$.

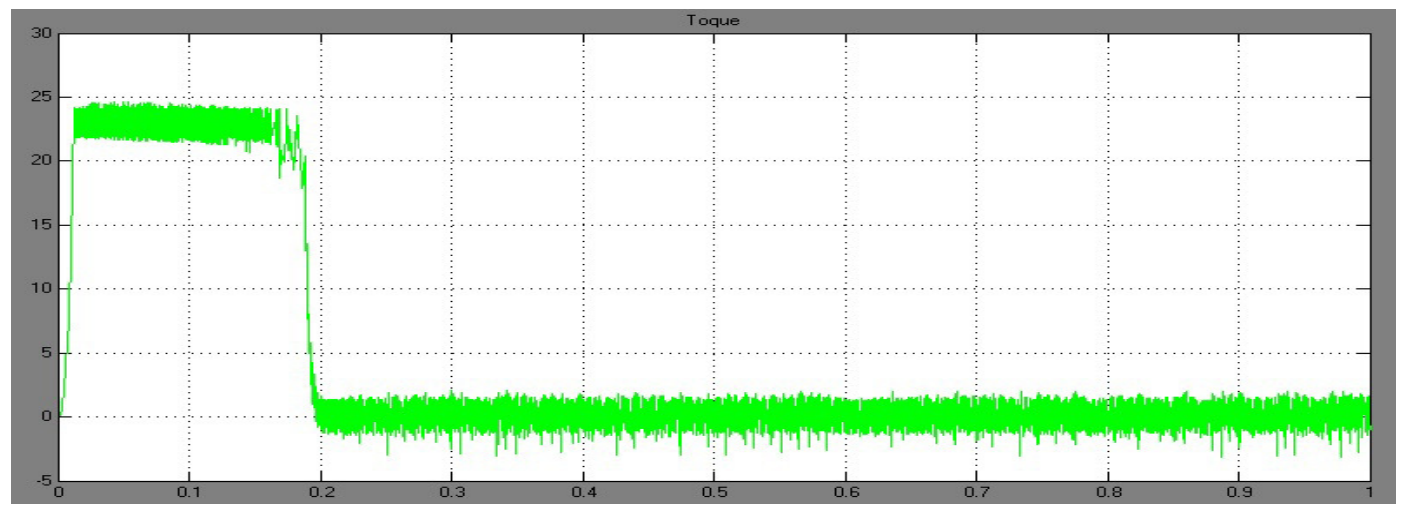

Fig 8: No load response for FLC based SVM DTC at fixed speed $150 \mathrm{rad} / \mathrm{sec}$.

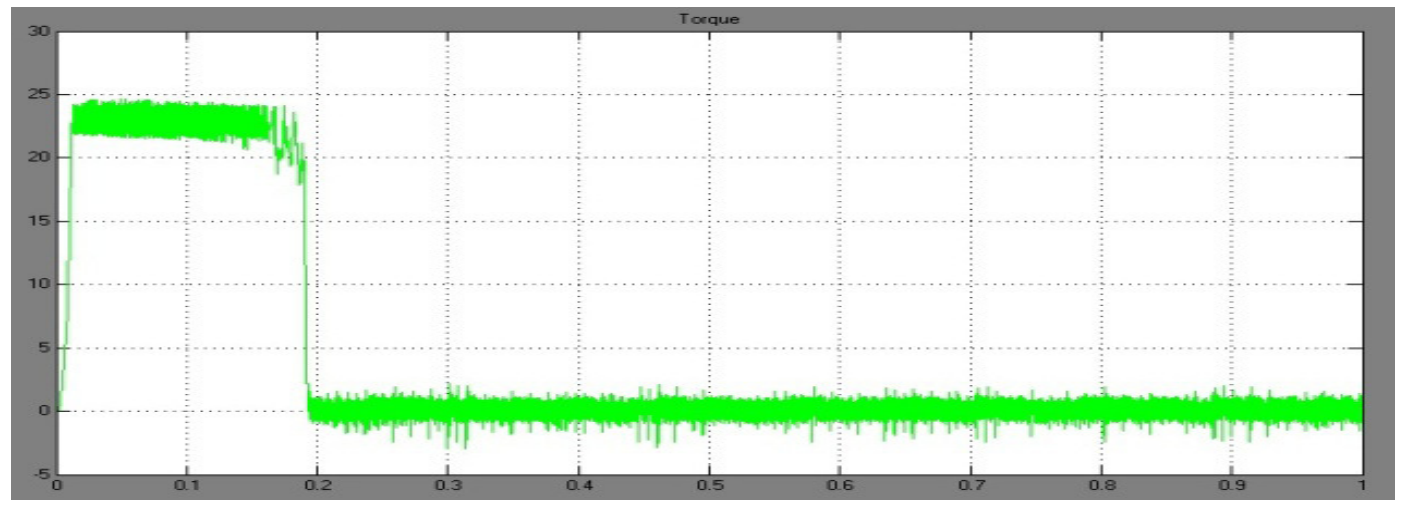

Fig 9: No load response for Hybrid Controller based SVM DTC at fixed speed $150 \mathrm{rad} / \mathrm{sec}$. 
Electrical and Electronics Engineering: An International Journal (ELELIJ) Vol 5, No 3, August 2016

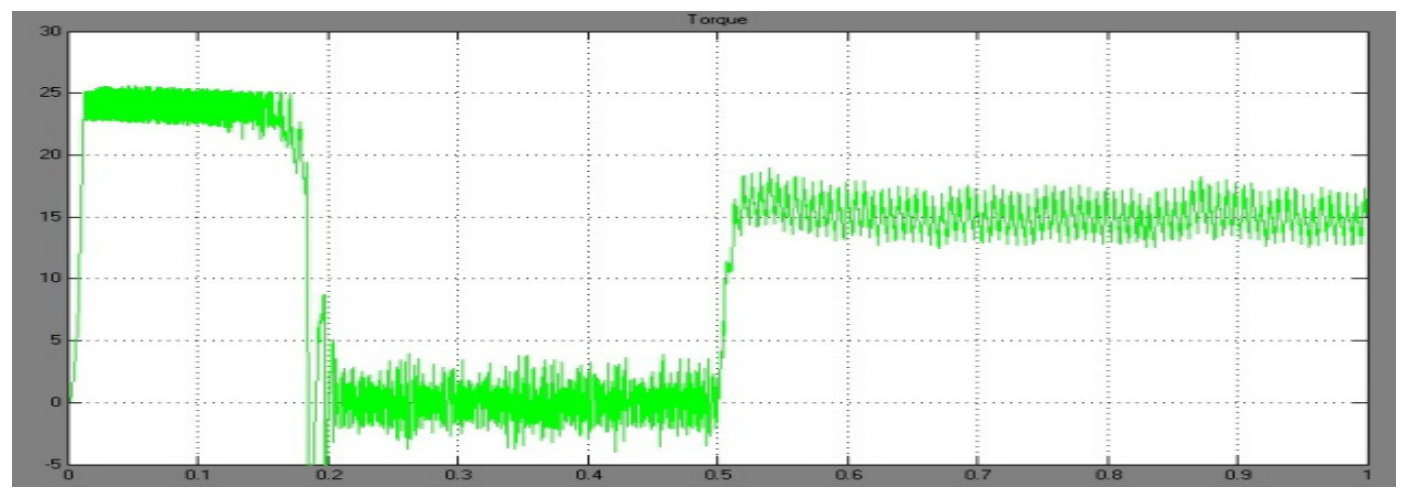

Fig 10: Load torque response of $15 \mathrm{~N}-\mathrm{m}$ at $0.5 \mathrm{sec}$ for PI controller based SVM DTC at fixed speed 150 $\mathrm{rad} / \mathrm{sec}$.

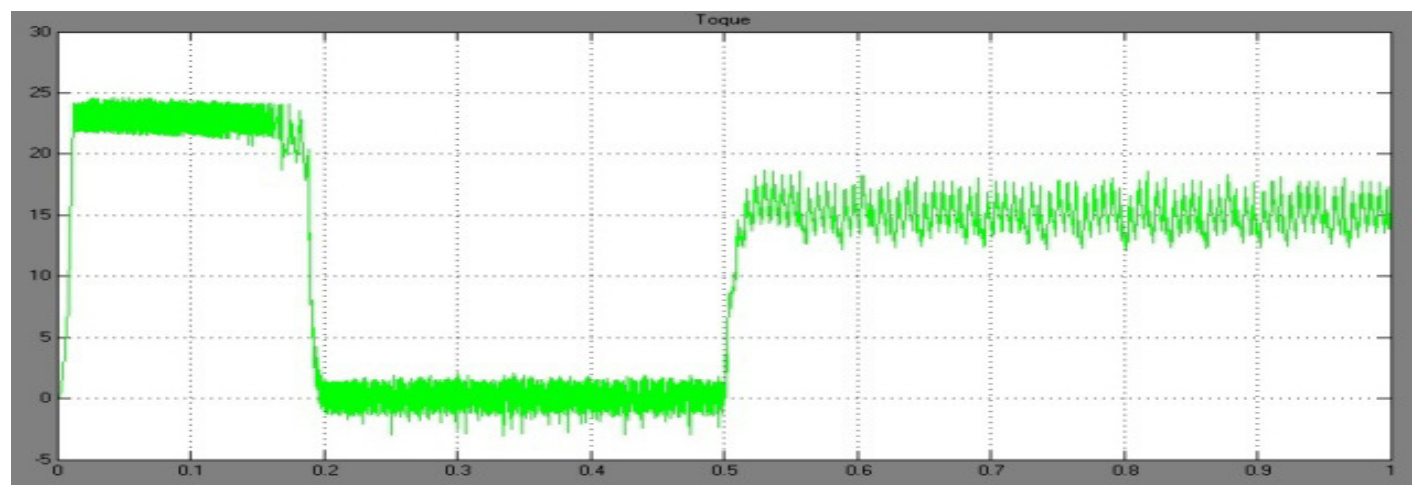

Fig 11: Load torque response of $15 \mathrm{~N}-\mathrm{m}$ at $0.5 \mathrm{sec}$ for Fuzzy Logic Controller based SVM DTC at fixed speed $150 \mathrm{rad} / \mathrm{sec}$.

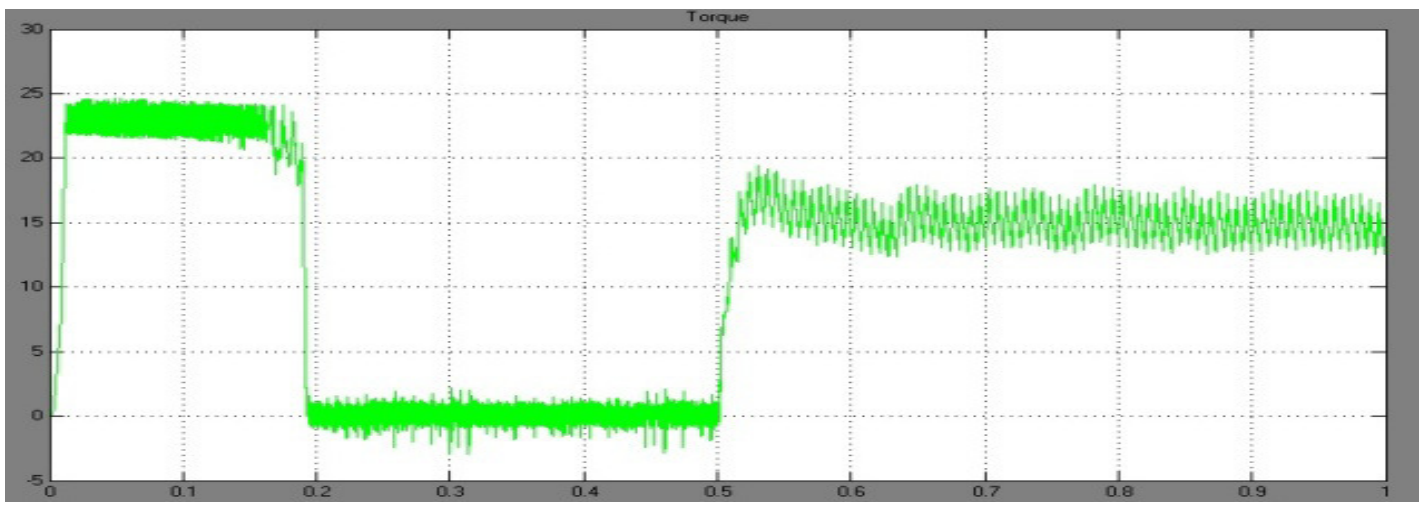

Fig 12: Load torque response of $15 \mathrm{~N}-\mathrm{m}$ at $0.5 \mathrm{sec}$ for Hybrid controller based SVM DTC at fixed speed $150 \mathrm{rad} / \mathrm{sec}$. 
Electrical and Electronics Engineering: An International Journal (ELELIJ) Vol 5, No 3, August 2016

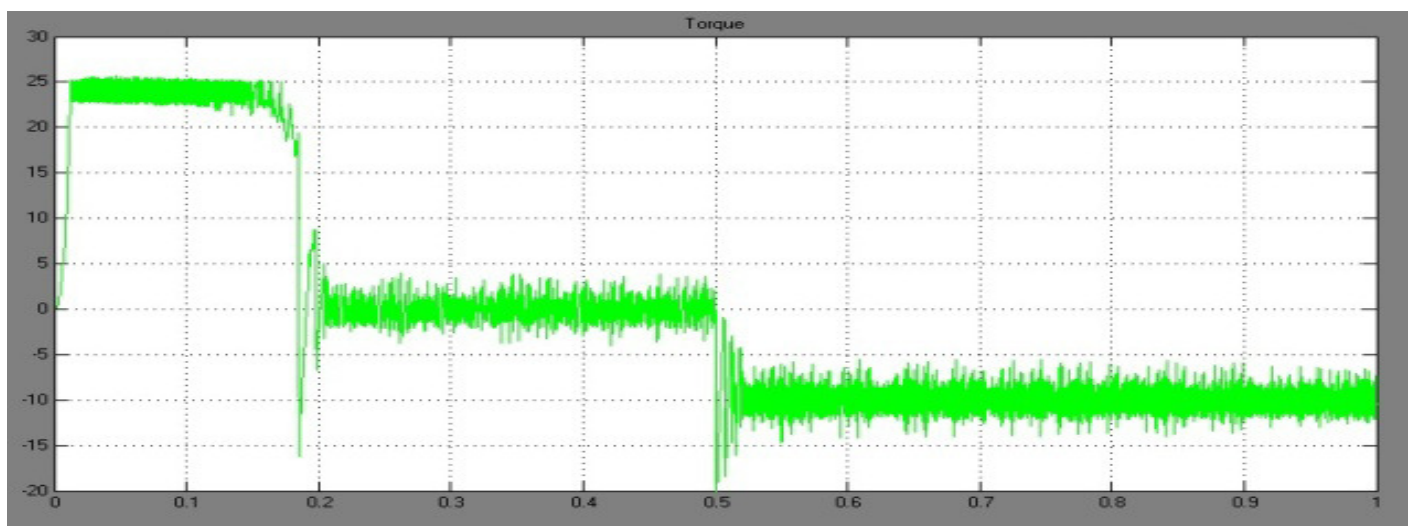

Fig 13: Load torque response of $-10 \mathrm{~N}-\mathrm{m}$ at $0.5 \mathrm{sec}$ for PI controller based SVM DTC at fixed speed 150 $\mathrm{rad} / \mathrm{sec}$.

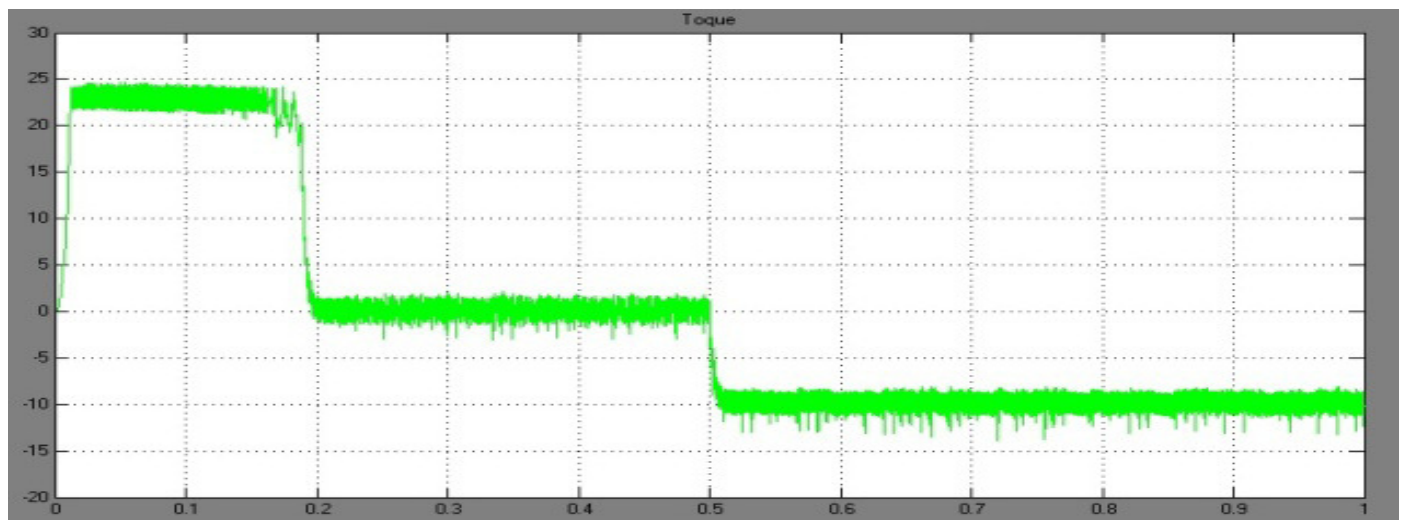

Fig 14: Load torque response of $-10 \mathrm{~N}-\mathrm{m}$ at $0.5 \mathrm{sec}$ for Fuzzy logic controller based SVM DTC at fixed speed $150 \mathrm{rad} / \mathrm{sec}$.

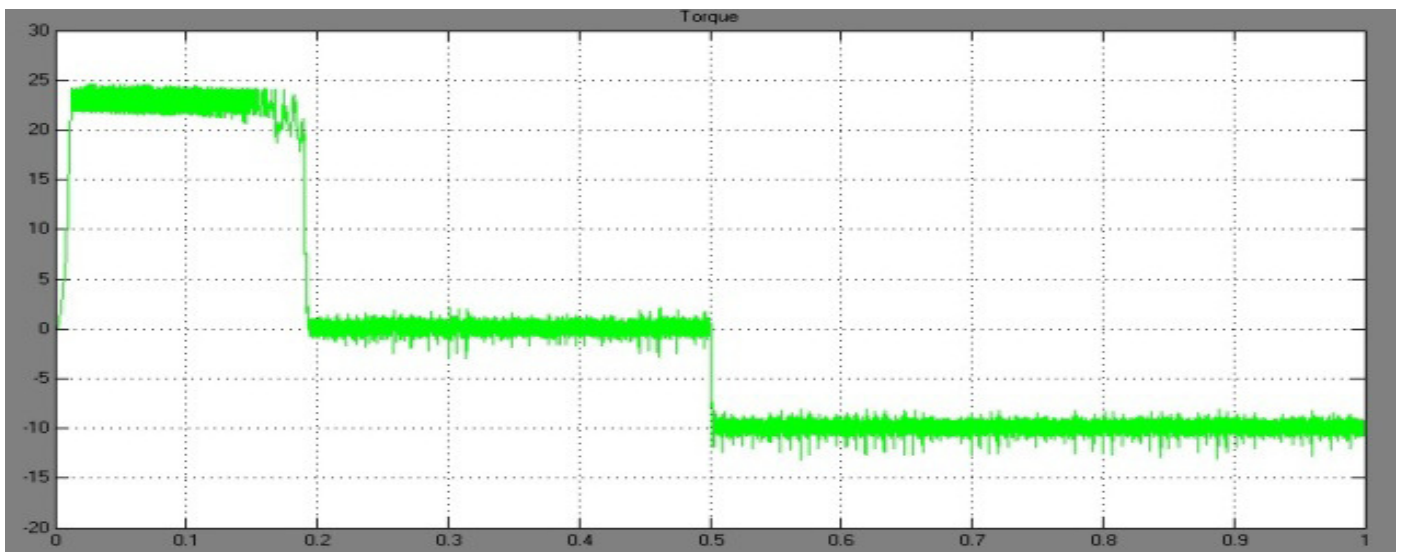

Fig 15: Load torque response of $-10 \mathrm{~N}-\mathrm{m}$ at $0.5 \mathrm{sec}$ for Hybrid Controller based SVM-DTC at fixed speed $150 \mathrm{rad} / \mathrm{sec}$. 
The variations with regard to the motor torque from fig.7 to fig. 15 using different control techniques from no-load to nearly $3 / 4^{\text {th }}$ load were obtained. Fig.7, fig. 8 and fig.9 exhibit no-load torque response using PI, Fuzzy and Hybrid controllers whereas fig.10, fig. 11 and fig. 12 explain the torque behaviour when a load torque of $15 \mathrm{~N}-\mathrm{m}$ is applied at $0.5 \mathrm{sec}$. Further a passive load torque of $-10 \mathrm{~N}-\mathrm{m}$ is added to the system at $0.5 \mathrm{sec}$ to depict the operation of the motor during transient mode. From all the simulated results listed above, the optimized torque waveform with reduced ripple is obtained by using Hybrid controllers.

\section{Conclusions}

Under various operating conditions, the improved performance of Space Vector Modulation based DTC three level VSI fed Induction Motor with Hybrid Controller has been simulated and studied. The proposed method (Hybrid Controller) results are compared with Fuzzy Logic controller and PI controller. Significant torque and flux ripple optimization has been achieved using Hybrid Controller. Therefore, SVM-DTC method can be a better solution for general purpose IM drives in the wide power range applications. It may be inferred that such method will continue to play a very important role in the development of high performance induction motor drives.

\section{APPENDIX - A}

\section{List of Principal Symbols}

$\begin{array}{ll}d^{e}-q^{e} & \text { Synchronously rotating reference frame direct and quadrature axes } \\ V_{d s} & \text { d-axis stator voltage } \\ V_{q s} & \text { q-axis stator voltage } \\ V_{d r} & \text { d-axis rotor voltage } \\ V_{q r} & \text { q-axis rotor voltage } \\ i_{d s} & \text { d-axis stator current } \\ i_{q s} & \text { q-axis stator current } \\ i_{d r} & \text { d-axis rotor current } \\ i_{q r} & \text { q-axis rotor current } \\ R_{s} & \text { Stator resistance }\end{array}$




$\begin{array}{ll}\lambda_{d s} & \text { d-axis stator flux linkage } \\ \lambda_{q s} & \text { q-axis stator flux linkage } \\ \lambda_{d r} & \text { d-axis rotor flux linkage } \\ \lambda_{q r} & \text { q-axis rotor flux linkage } \\ \omega & \text { stator angular frequency } \\ \omega_{r} & \text { rotor electrical speed }\end{array}$

\section{REFERENCES}

[1] Takahashi, I. and Noguchi, T. "A new quick-response and high efficiency control Strategy of an induction motor." IEEE Transactions on Industry Applications, vol.22, No. 5, pp. 820-827, 1986.

[2] Bose, B. K.; "Power Electronics and AC Drives". Prentice-Hall. 1986.

[3] MATLAB Fuzzy logic toolbox user guide. The Math Works, Inc, 1999.

[4] S.W. Lee,S.Kim \& Y.Park,(1998), "Fuzzy Pre-Compensated PI Controller For A Variable Capacity Heat Pump", In proceedings of the IEEE Conference on control Applications, pp953-957.

[5] M. N. Uddin and H. Wen, "Development of a self-tuned neuro- fuzzy controller for induction motor drives," IEEE Trans. Industry Applications, Vol.43, No. 4, July/Aug. 2007.

[6] I. Miki, et al. "Vector control of induction motor with fuzzy PI controller," IEEE Conf., IASAnnu. Meeting 1991, Vol. 1, pp.341-346.

[7] K. V. Naresh, Investigation of SVM-PWM based Induction Motor Drives, M Tech Dissertation, Indian Institute of Technology Roorkee, 2007.

[8] V.Chitra, R.S.Prabhakar, Induction Motor Speed Control using Fuzzy Logic Controller, World Academy of Science, Engineering and Technology 23, 2006.

[9] Dumitru D., Chemin B.,"A PI-Fuzzy Controller Designated For Industrial Motor Control Application”. AIAA, 1990, pp.949-954.

[10] R.Toufouti, S.Meziane, H. Benalla, "Direct Torque control for induction motor using intelligent techniques", Journal of Theoretical and Applied Information Technology, vol. 3, no. 3, pp. 35-44, 2007.

[11] Y. S. Lai and J. H. Chen, "A new approach to direct torque control of induction motor drives for constant inverter switching frequency and torque ripple reduction," IEEE Trans. Energy Conv., vol. 16, pp. 220-227, Sept. 2001.

[12] Hui-Hui Xiao, Shan Li, Pei-lin Wan and ming-Fu Zhao, "Study on Fuzzy Direct torque Control System ", Proceedings of the Fourth International Conference on Machine Learning and Cybernetics, Vol. 3, pp. 1537-1540, 2002. J. Clerk Maxwell, A Treatise on Electricity and Magnetism, 3rd ed., vol. 2. Oxford: Clarendon Press, 1892, pp.68-73. (Book) 